\title{
Unknown Suns: Laszlo Hudec, Antonin Raymond and the Ris- ing of a modern Architecture for Eastern Asia
}

\author{
Anamaria Andreea Anghel ${ }^{1}$, Joseph Cabeza-Lainez ${ }^{2 *}$ and Ying Ying $\mathrm{Xu}^{3}$ \\ 1 Department of Architecture, Faculty of Architecture and Urban Planning, Politehnica University of \\ Timisoara; Str. Traian Lalescu Nr. 2/A 300 223. Romania andreea.anghel@upt.ro. \\ 2 Department of Architectural Composition. University of Sevilla, 41012, Sevilla, Spain. crowley@us.es \\ 3 Department of Oriental Studies. University of Sevilla, 41002, Sevilla, Spain. xying@us.es \\ * Correspondence: crowley@us.es; \\ + The three authors contributed equally to this research
}

\begin{abstract}
The purpose of this article is to disclose the strenuous efforts of Laszlo Hudec in China and Antonin Raymond in Japan and India to create a modern architectural stance by heralding an incipient space syntax. In the turn of the $19^{\text {th }}$ Century, for dynastic, politic and economic reasons, Eastern Asia had very little modern Architecture. It is a surprising fact that, out of happenstance, two European architects Antonin Raymond and Laszlo Hudec, had to intervene to remedy this situation, to the point of becoming $20^{\text {th }}$ Century icons in Japan and China. Their fruitful careers spanned over thirty years and included locations, like Tamil Nadu or the Philippines. The Oriental territories were not an easy ground for the bold architectural achievements that they produced. Despite of faraway strangeness and uncountable personal losses, in revolutions and wars, which eventually forced them both to leave for the United States of America and never to return, they were successful in the manner of establishing a broad avenue for Modern Asian Architecture which is still recognisable today thanks to their systematic approach. However, theirs is an endangered heritage and the intention of this article is to be a just remembrance of in which way such actions could be performed, how they predated by many years a syntactic approach to architectural composition and why their legacy should be preserved.
\end{abstract}

Keywords: Modern Architecture in East Asia; Architectural Design; Laszlo Hudec; Antonin Raymond; Innovative Architectural Projects. Space Syntax. Asian traditions.

\section{Introduction.}

A score of years ago one of the authors of this article, was present when the late and famed architect Peter Smithson delivered a speech to a devoted audience in the Architectural Association of Seville.

When the turn came to explain his acclaimed project for the furniture factory Tecta in Germany, he produced a slide with a map of Europe. Then he showed that the latitude of the construction site near Kassel was very similar to that of London, roughly 50 degrees 
north. Then, with a smile of confidence, he uttered to the listeners' surprise: This is a Known Sun... and he went onwards explaining the particulars of his design.

With such phrase, P. Smithson wanted to convey his great environmental concerns; he dared to work in this place of Germany because he deemed that the climate or at least the shadow casting of architectural forms were similar to that of his native London.

On the contrary, for Antonín Raymond and László Hudec, the eastern sun was a totally unknown one, no matter how hard they tried to appease its ruthless brightness.

Both Hudec and Raymond never chose such challenge. For sundry vicissitudes, including exile and imprisonment, they were conveyed to settle and design for Eastern Asia. They soon realized that their duty and position was to adapt the innovations of modern architecture which they had known in Europe and America, such as Perret's, Wright's or Le Corbusier's oeuvre [1], to the incipient but firm building activity of the great Chinese and Japanese newly opened ports. Subsequently they extended this huge task to all confines of Asia, like India, the Marianas and the Philippines.

In this article, the authors will try to disentangle the subtle nuances and mechanisms of such extraordinary construction.

When China and Japan opened up to European markets and culture in the $19^{\text {th }}$ century and began an amazingly rapid process of technological development, their traditional architectural culture was also fundamentally transformed. The two Eastern Europeans who contributed the most to this process of modernizing the architectural image of the Far East, blending local traditions with European influences and creating the foundations of contemporary architecture in both countries, were the internationally recognized Czech Antonín Raymond and László Hudec, yet to be rediscovered by posterity. [2]

The careers of Hudec and Raymond [1,3] share considerable similarities. They were born geographically close to each other (Czechoslovakia), although under different circumstances, and ended up in a cultural environment foreign to their own. The two architects had an active and productive career, enabling them to form ties with the members of the local cultural and political elite. They both strived to find their own form of expression in the 1920's and clearly turned towards Functionalism in the 1930's, exerting a major influence on their respective environments. While they enjoyed international attention thanks to periodicals and other publications. This led them to make a fundamental contribution to the modern development of architecture in the metropolises of the East. 


\section{The material milieu}

2.1.- Antonin Raymond and Laszlo Hudec, short comparison between their trajectories from Europe to Eastern Asia (Fig.1).

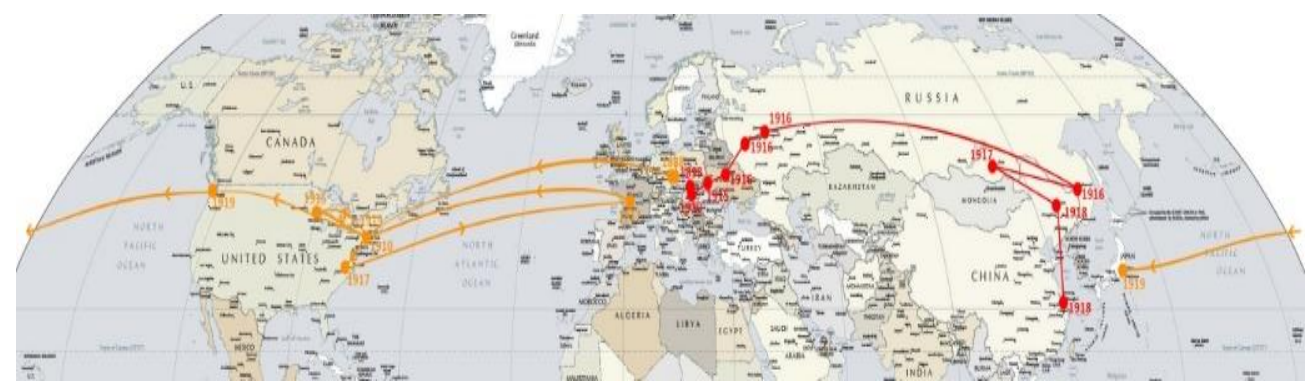

Figure 1. Comparison between Hudec and Raymond's trajectory from Europe to Eastern Asia (Hudec's trajectory in red, Raymond's trajectory in orange).

Raymond and Hudec, since the beginning of their lives, shared many similitudes like: the birthplaces which are very close, one in today's Czech Republic and the other in Slovakia; years of birth, with a slightly difference of about five years, 1888/1893; their dream to excel in architecture; their formation at the architectural academy; First World War and their active participation in it; and their destiny in Eastern Asia.

As we can see in the map above, their trajectories start from similar places, but Hudec is going East and Raymond West. Both converge in Eastern Asia, one in Shanghai and the other in Tokyo. The big difference between the two is that Hudec arrived in China unwillingly, after escaping from a prisoner camp during the War [2], and Raymond came to Japan (with his family and Frank Lloyd Wright) with the precise aim, of designing the Imperial Hotel.

As regarding their professional careers, immediately after finishing his studies, Hudec was enrolled in the army. The only experience he had was the one of working for his father. This was a blessing in disguise for him, although he had to start practically from nothing in Shanghai, he rapidly progressed and evolved.

On the contrary, Raymond's work experience before arriving to Japan was ample. He had always combined two professions, architectural practice and painting. He worked for different architects and painted together with his wife. It was because of his talent that he was invited by Frank Lloyd Wright to help him with the design of the Imperial Hotel in Tokyo. [4]

2.2 China and Japan, summary of relevant history and relations in the $20^{\text {th }}$ century:

China and Japan are situated in Eastern Asia and are geographically separated by a relatively narrow stretch of ocean. Japan was strongly influenced by China's writing system of characters, architecture, culture, religion, philosophy, and law.

In the mid-19th century, Western countries forced Japan to open for trading. Japan moved towards modernization (Meiji Restoration) and started to view China as an antiquated and isolated civilization, unable to defend itself against Western forces in part due to the First and Second Opium Wars resulting in Anglo-French Expeditions from the 
1840s to the 1860s. Japan's long chain of invasions and war hostilities in China between 1894 and 1945 as well as modern Japan's attitude towards its past are major issues affecting current Japanese and Chinese relations.

2.3.- Oriental Asia, Shanghai and Tokyo and the making of modern architecture:

Like every other style in architecture, Chinese architecture is a style that has ingrained in Eastern Asia since the beginnings of the Chinese civilization. The structural principles are almost the same, differences reside mainly in the decorative details. Chinese architecture had major influence on the architectural styles of Korea, Vietnam and Japan.

In the $20^{\text {th }}$ century, after the opening of China to the world, western-trained Chinese architects have tried to combine traditional Chinese design into modern architecture. This had limited success in big cities, like Beijing or Shanghai, and later proved impractical because of the pressure for urban development, which demanded new types of buildings. The appreciation for low-rise Chinese architecture, declined in favour of modern architecture.

It is important to outline the main characteristics of traditional Chinese architecture, in order to analyse the buildings designed by the architect Lazlo Hudec, among the pioneers who brought modernism into design. These features are, from the point of view of space syntax [2]:

1. symmetry - signifying balance and order

2. enclosure - this involves designing the building around an open space, like a courtyard, the spaces were opening to the yard directly or through verandas

3. hierarchy - the placement of the building within a complex, taking into account the entrances to the different buildings

4. horizontal emphasis - the emphasis on breadth and less on the height of the buildings

5. cosmological concepts - the use of concepts, such as Feng-Shui and Daoism, for the organization and layout of the constructions (In Japan, China, India and other countries the disposition of buildings in relation to the surroundings followed an adroit strategy of natural balance related to geomancy like Feng-Shui or Vastu and to the observance of deeply rooted environmental rules. [1])

Shanghai gained its international identity and flourished as a hub between the East and the West during the period known as Old Shanghai, which dates from 1846 to 1945. Shanghai was then a free treaty port, witnessing the establishment of international settlements. During its internationalization period, Shanghai gained its cosmopolitan reputation through the intermixture of global and local residents with diverse social, economic, and cultural backgrounds. This intersection of cultures is reflected in the mixture of multinational architectures and the coexistence of modern and traditional styles.

Historically, although Japanese architecture was strongly influenced by its Chinese counterpart, there are some important differences between the two. For example: the wood used in the Chinese buildings is finished with bright painting while in Japanese 
traditional architecture the wood remains exposed, Chinese architecture is based on a lifestyle that uses chairs, tables and beds while in Japan the floor serves all this purposes [5], this changed slightly during the Meiji Period (1868-1912).

László Hudec, in one of his letters addressed to his family, writes his opinion about Japanese and Chinese temples and the differences between them: The concept of Chinese temples is absolutely beautiful and on a large scale, but shameful in the detail of its workmanship - while in Japan the details are like arts and crafts but the layout is weak. It is true that their asymmetrical arrangement is much more picturesque than the strict symmetry of the Chinese temples but the trees in the courtyards make the latter less boring. [2]

Traditionally Japanese architecture is characterized by wooden structures, slightly elevated from the ground, covered by tiled or thatched roofs and with sliding panels, translucent and covered by paper, which are called respectively shoji and fusuma. Rash mats or tatami, heavily modulate the space at a fixed area of $1.65 \mathrm{~m}^{2}$, two tatami disposed in a square shape give $3.3 \mathrm{~m}^{2}$, which is the actual unit of measurement, the tsubo. Even today, these are key elements of the traditional Japanese house and garden [6]. These sliding panels or shoji are elements particular to Japanese architecture, used instead of normal walls and thanks to them each space can be customized for different occasions. Until the 20 century, tables, chairs or beds did not exist in any house or space, traditionally, the Japanese people used the floor for sitting or sleeping.

Architecture in Japan has been strongly influenced by the climate and this is reflected in the way homes are built. Summers in most of Japan are long, humid and hot. This is also the reason why the traditional houses are raised from the ground for letting the air circulate around and beneath the house. Wood is the preferred material because of its properties- cool in summer, warm in winter and its flexibility during the earthquakes.

Since the $19^{\text {th }}$ century, gradual changes began. Japan has slowly incorporated Western modern architecture into the design of buildings. Today, Japan is a trend setter in the field of architectural design and technology. Modern architectural techniques were introduced in Japan with the advent of the Meiji Restoration in 1868. Two major events in the history of Japan changed radically its architecture. The first event was the Kami and Buddhas Separation Act of 1868, which distinguished Buddhism (foreign faith) from Shinto and Buddhist temples from Shinto shrines, breaking an association which lasted well over a thousand years. This caused severe damage to the nation's architecture for lack of State funding. The second event was the intense modernization Japan was undergoing in order to compete with other developed countries. For this, the first step was importing architects and styles from abroad. But after a while, Japan has taught its own architects and slowly began to design in their own modern style. Japan sent architects to the west to study and they returned home introducing the International Style of Modernism into Japan. International recognition has come only after the Second World War with the work of architects like Kenzo Tange. In the four years of employment in the office of Kunio Maekawa starting in 1938 (one of the most influential Japanese architects of his generation), Kenzo Tange assimilated his practising experience. Maekawa had the privilege of working in the office of Le Corbusier in Paris [6] (being part of the team which 
designed the Villa Savoye and the Swiss Pavilion) and, once returned in Japan, he spent five-years at Antonin Raymond's office.

In the 1880s, a sudden the reaction against the rush toward Westernisation, ignited the support of Asian models, even in Architecture. This changed again, after World War I, when the architects Frank Lloyd Wright (1869-1959) from the United States and Bruno Taut (1880-1938) from Germany arrived to work in Japan.

\section{4.- Interior design concepts for the Japanese dwellings}

The interior design of a Japanese house is very different from normal European interiors. It possesses its own rules, underlying deep notions based on tradition. In the past, a Japanese house consisted of an open space, even devoid of screens to make partitions for individual spaces. In time, particular areas and different functions (like eating, sleeping or dressing) became more and more present in the design. Because of such new necessities, the use of self-standing screens started (first byobu, then shoji and fusuma). They were used to provide some degree of privacy, although they served less as sound barriers. These screens can be easily removed in order to open up the entire space. [5]

The Japanese had a particular way of dealing with the interior and exterior of the house. Instead of seeing the interior and exterior as two distinct environments, they are considered continuous spaces. Therefore, they introduced the veranda (engawa), which plays the role of transitional space between inside and outside.

The traditional living space is designed for people who remain seated on the floor, not standing. Because of this, the windows and doors are placed low, so that the visual relation between the spaces is clear and everyone from the inside can see the garden or vice versa.

Although modernization has produced significant alterations in the way of designing, the traditional Japanese style has not vanished, and it is still in use. For example, even in westernized dwellings, it is likely to find a room whose floor is clad with tatami and it is customary to remove one's shoes when entering the house.

\section{3.- Case Studies}

3.1.- Antonín Raymond and László Hudec comparative works during the World War intermission

The architects both lived and practiced in Eastern Asia, for a long period of time, sufficient to allow them to become involved with the local people and culture. They had the advantage of starting their architectural practice in Japan and China, in the proper period, when these countries opened up to modernization; they were "in the right place at the right time". A timeline of their careers is offered in Figs. 2 to 4.

In Raymond's case, just when Japan's pursuit of modernization slowly shifted from being based on the westernization model to a drawback towards the native roots. Another important reason for Raymond's blossoming career was the fact that he benefited from 
the consequences of the Great Kanto earthquake and the following period of reconstruction. [4]

Laszlo Hudec was much more interested in the use of modern materials, functions and technologies. This was the main reason of their encounter. When Raymond was finishing his design for the American Otis Elevator Company in Tokyo, Hudec was installed Otis lifts for the first time in Shanghai in his novel 22 storey Park Hotel. As Alessa Hudec De Wet recalls, Hudec met Raymond through the Asian representative of Otis. After the family's first trip in 1932 to Tokyo, a lasting friendship developed between the two and their families. From 1935 to 1941 the Hudecs spent their summer holidays in Japan in Raymond's house on a hill near Karuizawa. [7] This can be inaccurate in part, because the Raymonds had to leave Japan in 1938.

On the other side, Antonin Raymond gained a deep insight into traditional building techniques, use of materials and on a wider scale into Japanese Culture. This allowed him to deal with the problematic issue of finding the perfect balance between the traditional Japanese and Western modern architecture, the necessary syntax to the creation of a modern architecture suited to Japan.

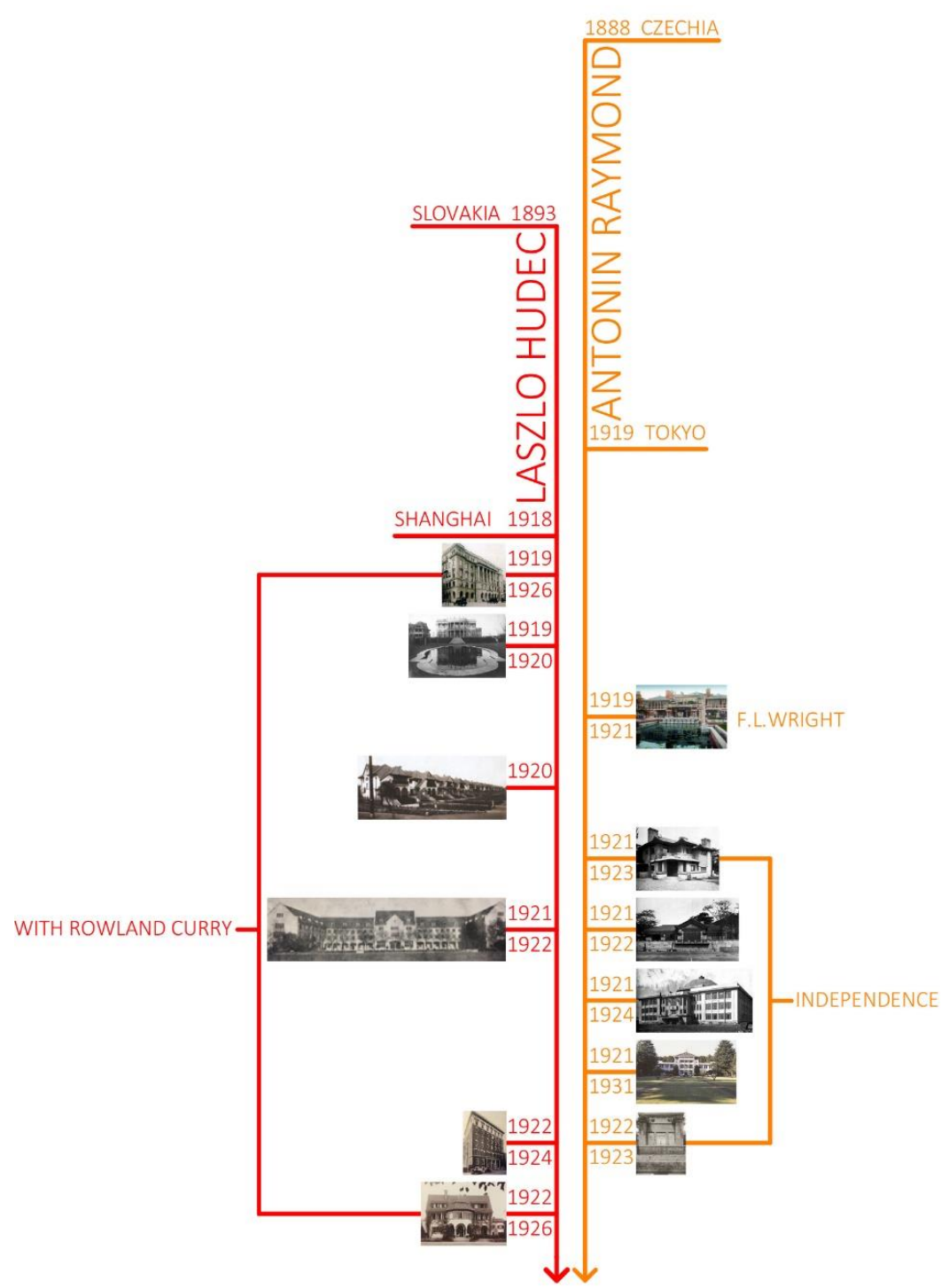

Figure 2. Timeline 01- Hudec and Raymond comparative designs. 


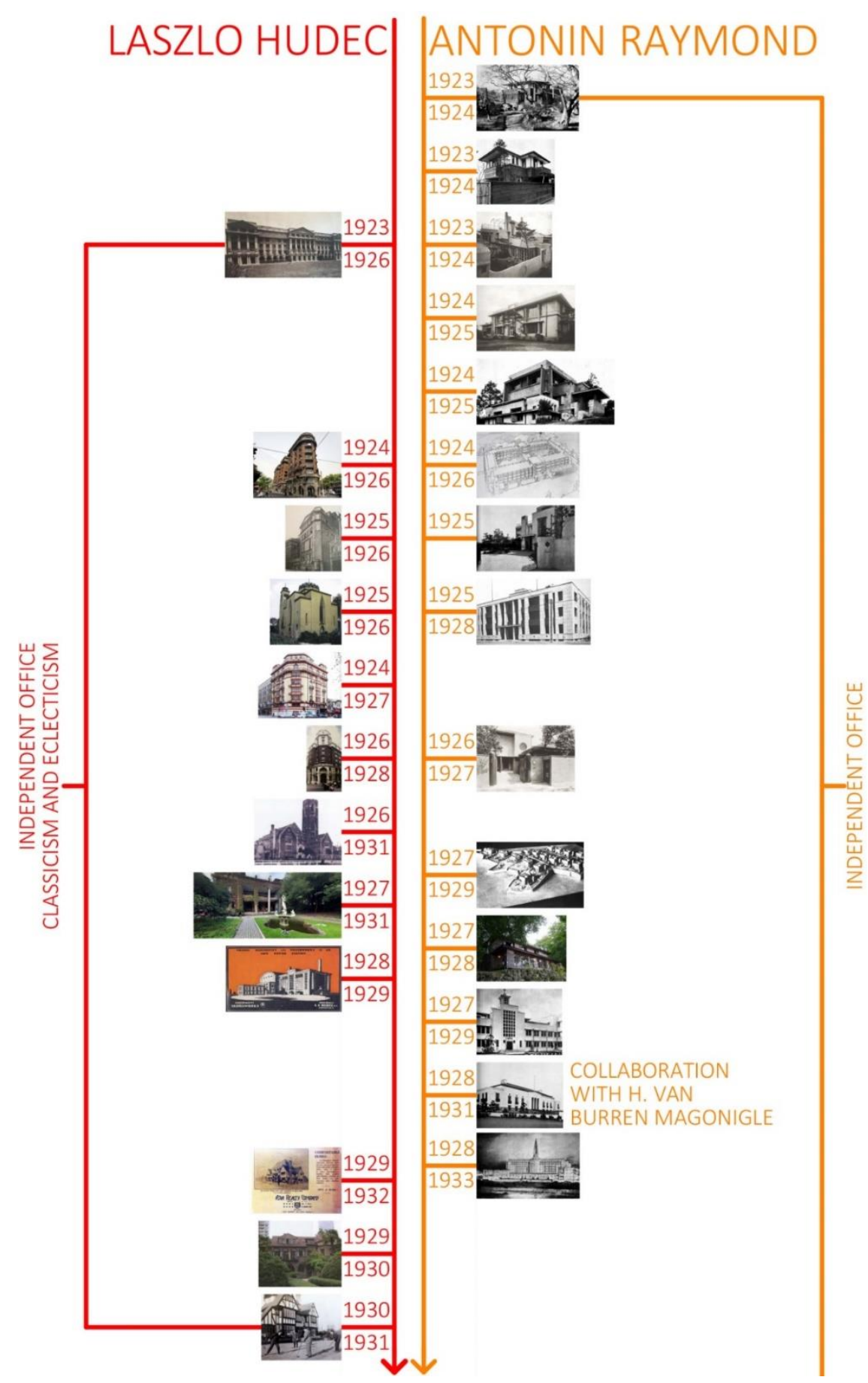

Figure 3. Timeline 02- Hudec and Raymond comparative designs. 


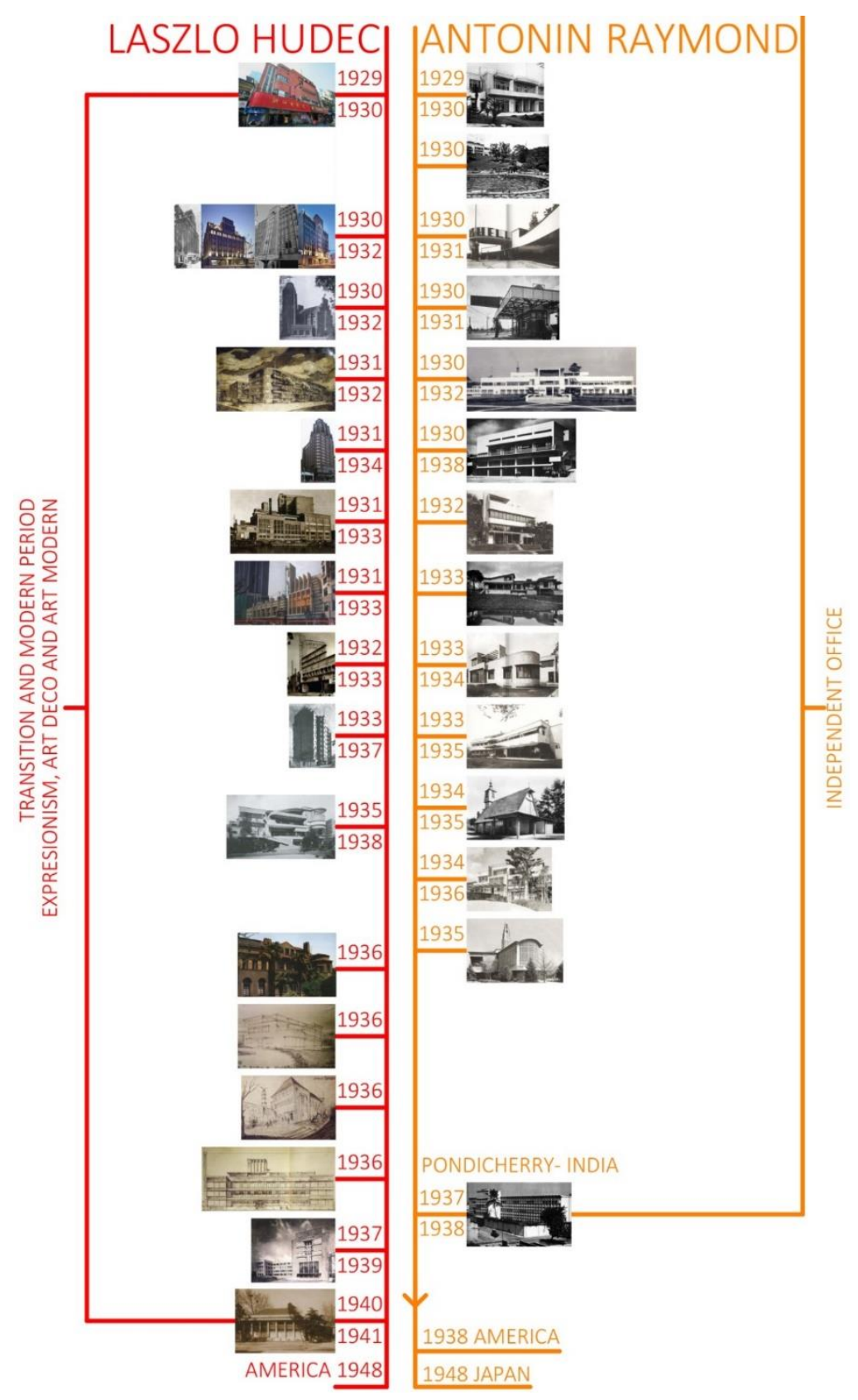

Figure 4. Timeline 03- Hudec and Raymond comparative designs.

3. 2.- Architects and their own houses:

The authors believe that the best way for an architect to achieve full development is by reflecting on the design of his own house. The process often starts as an experiment that later becomes a representative project. In Raymond's case this happened more than once but the first occasion was with his Reinanzaka concrete house (Fig. 5) which ended up to be a real modern project, one of his masterpieces. Designing his own house or his Karuizawa studio, an architect gains all the necessary freedom to create art which incorporates most of his knowledge, beliefs and principles. Without compromises and restrictions, this is the way how real art and architecture emerge. 

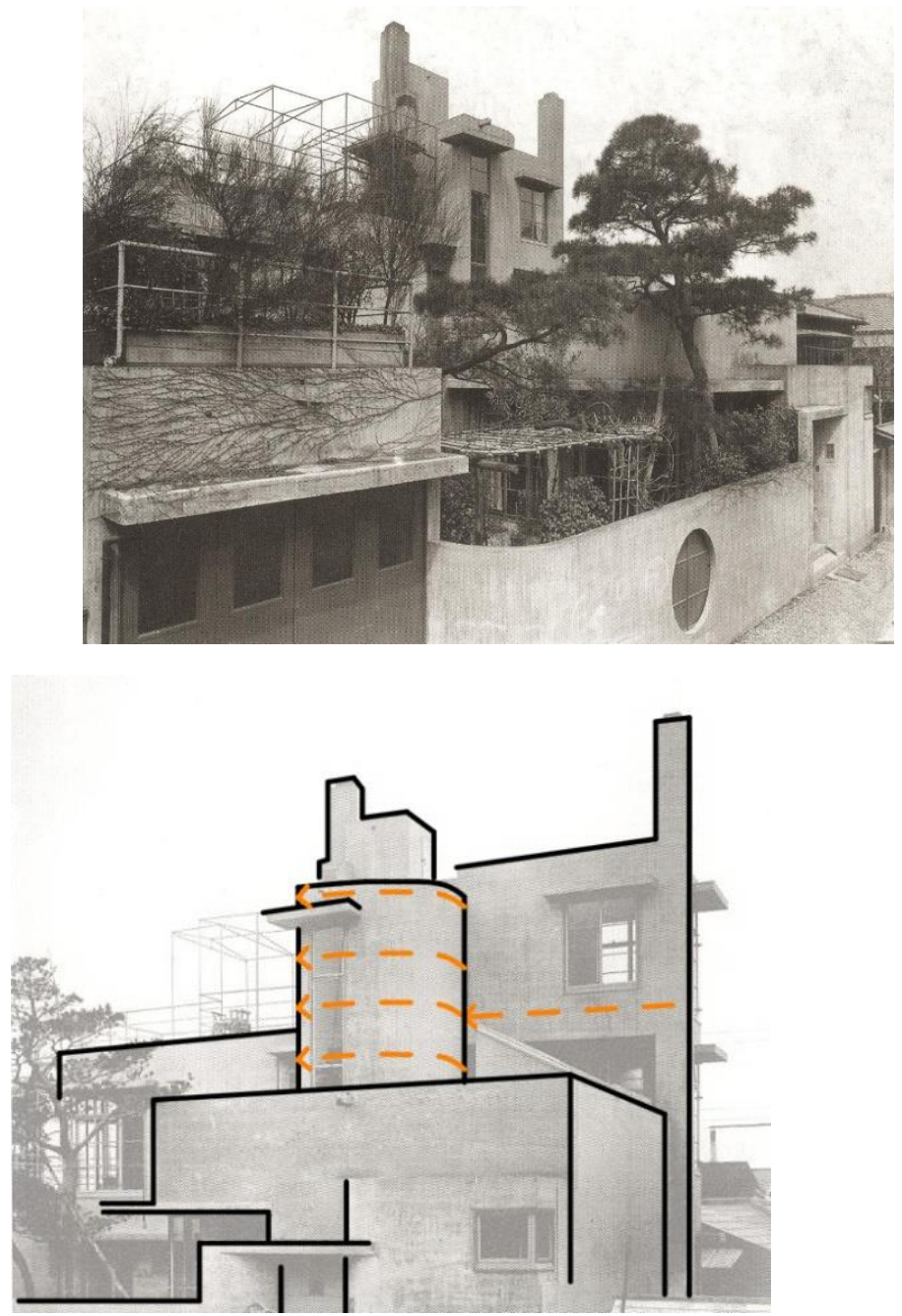

Figure 5. Reinanzaka house of the Raymond family 1924 and its concrete plasticity.

Built completely in reinforced concrete, Reinanzaka House constituted a huge step forward and a liberation from Frank Lloyd Wright's mannerism, predating modern architecture. Like everything Raymond designed after the Kanto Earthquake of 1923, the house had an earthquake proof structure of reinforced concrete. The exposed concrete was not clad with cement mortar or any other finishes which emphasized Raymond's belief in that, there is inherent beauty in concrete and it has its own character if studied and understood [5]. He created a monolithic enclosure surrounding the house and garden. The configuration was striking because it was dissimilar to his former designs and also to local production. For the organization and separation of the functions (the living areas from the servant's areas), he articulated three aisles under a U-shaped plan (Fig.6).

Raymond's own house was remarkable in a number of ways. It was one of the first occasions on which a concrete frame was enriched so as to recall traditional Japanese wooden construction, a mannerism which was to become the architectonic touchstone of Japanese Architecture after Second World War. [5] 


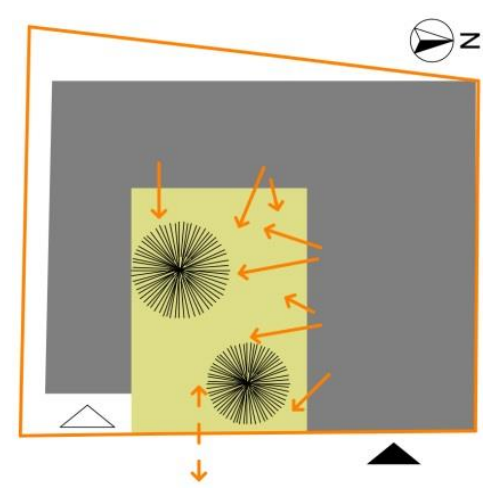

Figure 6. The U-shaped plan of the Reinanzaka house and openings towards the garden.

Raymond explains that the flexibility and southern orientation of the living spaces, the position of the windows which provided good ventilation and natural illumination and the principle of using only natural materials without any processing, were all inspired from the traditional Japanese examples. Because every room had proper orientation to the south and access to its own section of garden, the theme of the windows became quite important. There appeared some necessary details, above the windows "the overhang (eyelid) "which was not only aesthetically but had the main purpose of preventing direct sunlight in summer while admitting it in winter. Moreover, constituted a reinterpretation of the veranda (engawa), which has the combined role of a transitional space between inside and outside and a protection from the harsh weather. These concrete canopies or "eyebrows" situated over the windows became one of the principles of modern design [1]. In Raymond's attempt to integrate into his design, elements extracted from the local vernacular, the rain water was evacuated in a particular way, by means of ropes, instead of usual Western gutters prone to clogging. Apart from concrete, the house has metal fenestration and tubular steel trellises (Fig. 7). 


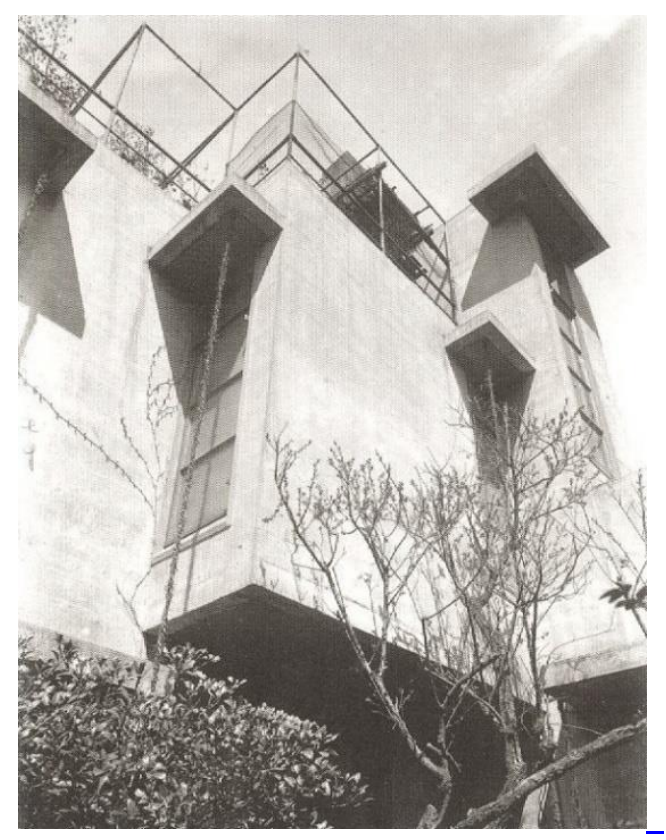

Figure 7. Reinanzaka house of the Raymond family 1924, detail of the concrete eyebrows and of the ropes for evacuating the rain water, looking up from the garden

In 1933, the Raymonds decided to build a summer residence (Karuizawa) for themselves in order to continue developing some of the work in the midst of the hot summer of Tokyo. Raymond had a deep admiration for Le Corbusier's oeuvre. In the design of his summer residence, the main inspiration was Le Corbusier's unrealized Matias Errázuriz house for Zapallar in Chile (1929-1930). In fact, as Raymond says, what better way to express an admiration for someone than taking one of his motifs of an unconstructed project and carrying it further on. Raymond's design borrowed the distinctive "butterfly roof and internal ramp circulation". "Except for the motif for the main room of the Karuizawa summer house, the building was conceived in an entirely original way. It has a very strong Japanese flavour, although it does not adopt any traditional Japanese forms." [5] The Karuizawa summer house may be a key project to the intention of breaking up completely from Wright's influence and embracing a new period, dominated by Le Corbusier.

Pointing out that on his turn, other architects used to adopt or borrow details from his designs, in 1938, Raymond published his book entitled "Architectural Details" The book was conceived with the aim of sharing his knowledge and information with all the interested architects "in the hope that they would use it" (like in his own case, when he was a student and first put his hands on a book presenting Frank Lloyd Wright's projects).

Raymond built a house suited to his family life style (one of the fundamental principles advocated by the pioneers of modern architecture). His main design principles: "honesty", "simplicity", "economy", "directness", "functionality" and "naturalness" are guiding lines of the whole structure.

For the plan and interior organization of the spaces Raymond followed the roles of Japanese traditional residential architecture regarding orientation. The plot has a pavilioned distribution. Raymond oriented the main house with the openings of the living room towards south, facing the breath-taking view of the mountains and the pond. (Fig.8) 
The house is composed of two main areas- the public area (living and dining room, kitchen and studio) and the private area (which included the bedrooms and the maid's room). These two main zones are articulated by the pool, which serves as natural barrier between them two, creating a source of relaxation, fresh and moist air which invigorates the atmosphere during the humid summer.

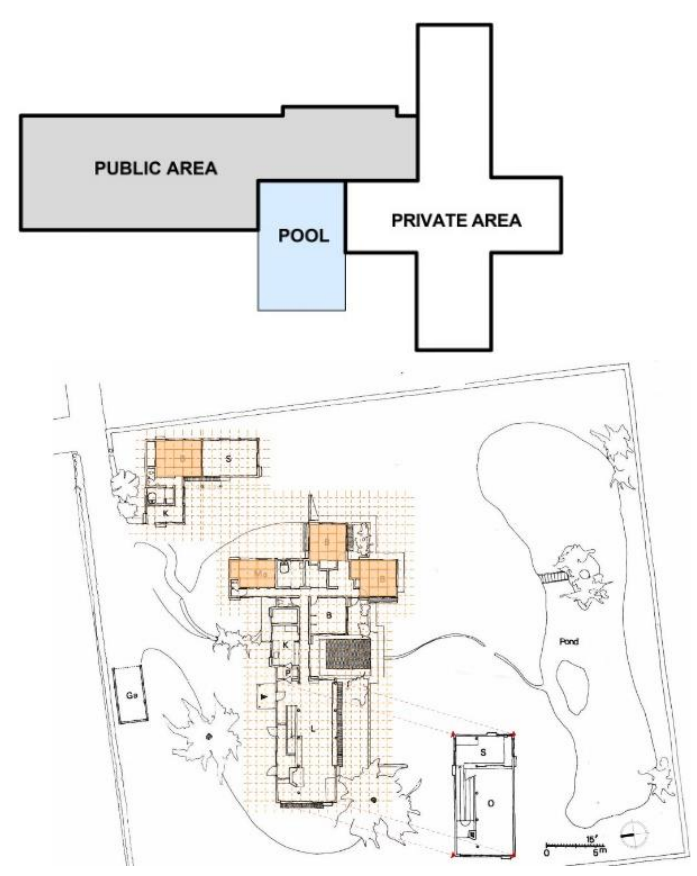

Figure 8. Karuizawa house, public and private area and the pool, plan and views.

The house stands upon an elevated ground, artificially created from the soil extracted to make the pond (Fig. 9). The circle of life is recreated by the fact that the water overflowing the pool is being let to the pond. In fact, the whole level difference allows better drainage of the ground below and around the house, for which the pond functions like a reservoir. (Fig. 10) The fact that is entirely supported by a series of short wooden posts facilitates the natural ventilation beneath the house. 


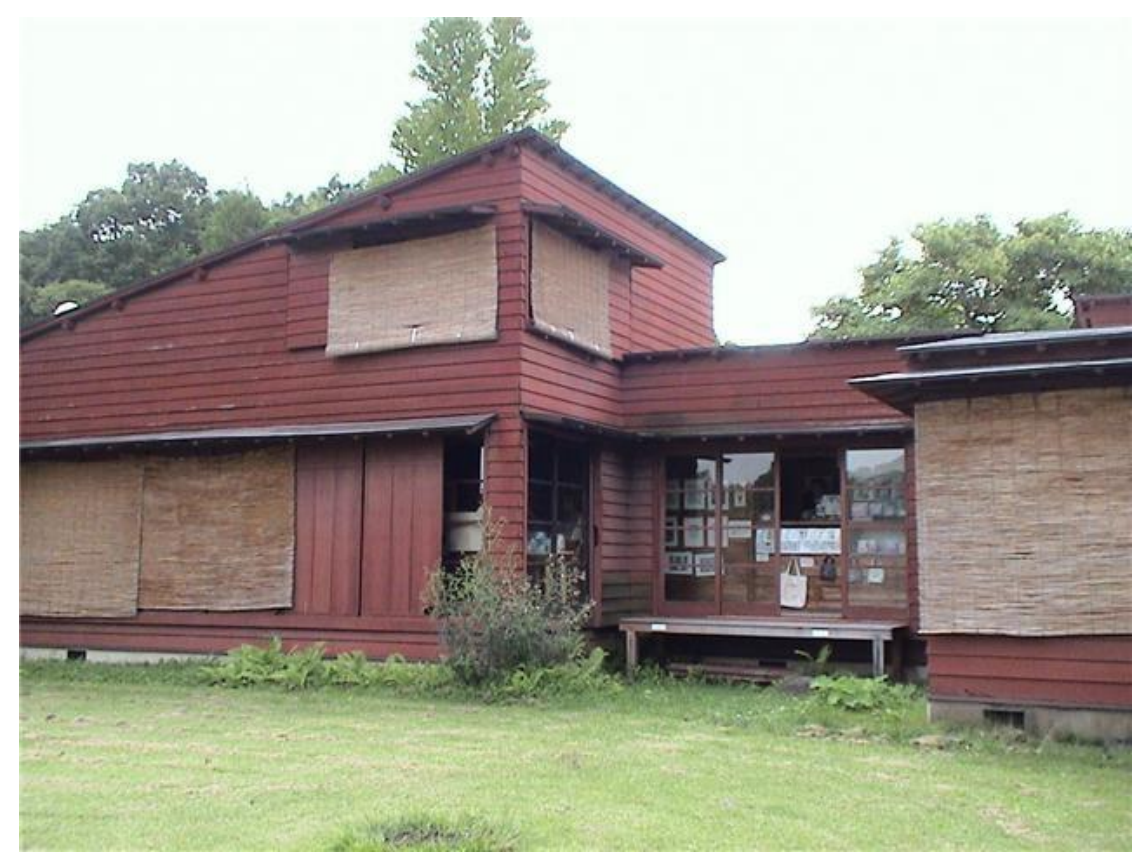

Figure 9. Karuizawa summer house, lightness and transparency

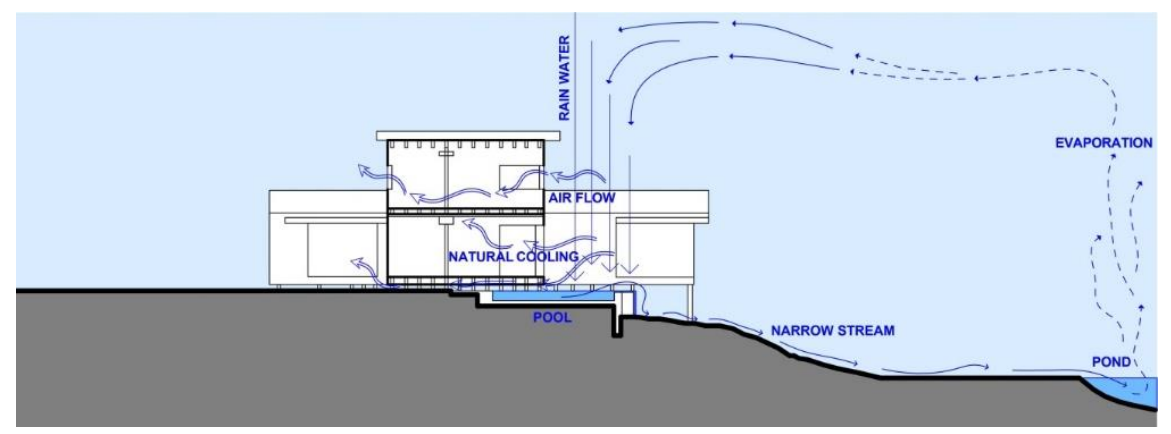

Figure 10. Karuizawa summer house, section, natural ventilation and water cycle = eco-friendly, sustainable house.

Raymond was eager to introduce traditional Japanese syntax of the tatami in his design. In the summer house there are 3 tatami rooms in the main building, almost the entire private area. By placing a grid based on a 3 by 3 shaku (Japanese foot) module over the plan, [8] we can observe that Raymond used the tatami as a syntactic resource for the overall plan composition of the Karuizawa house, highlighting the conversation between western and traditional Japanese. (Fig. 11 


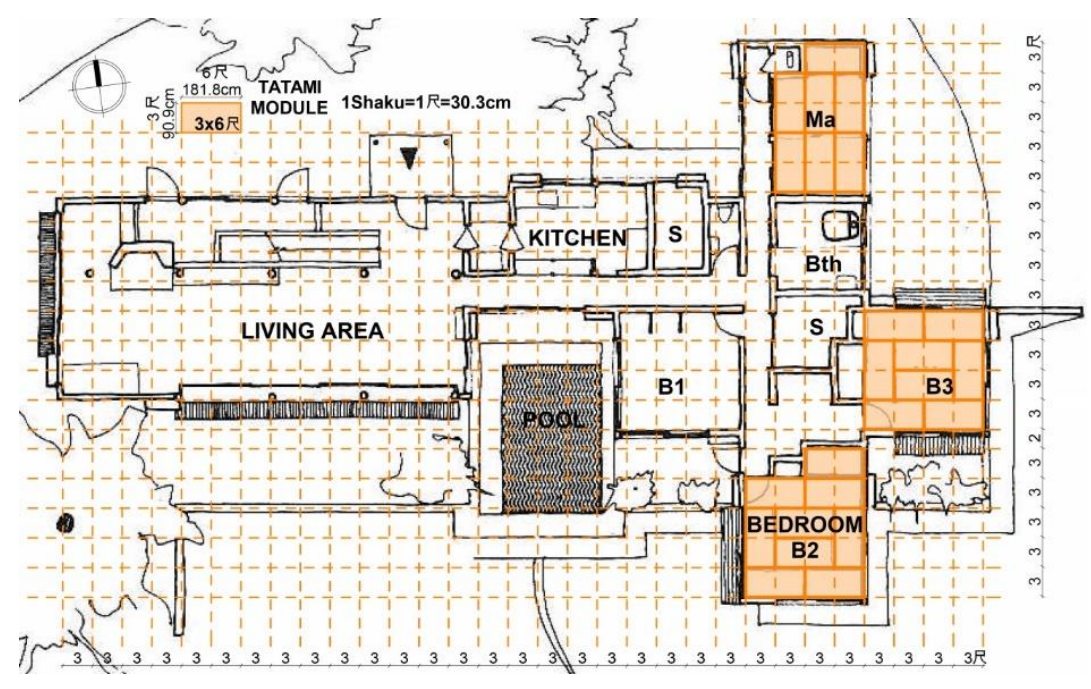

Figure 11. Karuizawa summer house, study of the tatami module over the plan.

This house "marked the new era in his design" in Raymond's own words. Actually, with this house, he completed a stage, summarizing all the knowledge gathered previously and it was the living result of the many years spent trying to find the perfect balance between Western modern principles and Japanese traditions. The need to combine western and Japanese elements in his designs was not only due to practical issues, but more an aftermath of his long studies and admiration of the Japanese roots and traditions. He began to develop this discovery from an early stage in his career. The Karuizawa summer house testifies the strong impact these researches had on him and his wife Noemi Pernessin, and practically used them as main inspiration for their ensuing designs. In the last period of their life they re-constructed the Karuizawa house in New-Hope, Pennsylvania, [5] under a loose key that permitted calling it a farm and that was sadly demolished recently.

For Raymond, the secret key to successfully blending modern with traditional Japanese architecture was the "wise handling of material that speak to us", in this case he linked concrete from lava aggregate and wood from neighbouring forests. The structure of the building included only these two materials, an exposed concrete elevated base with a round lumber framework of sand-polished columns and beams [9] (traditionally Japanese architecture is characterized by wooden structures, slightly elevated from the ground).

A clever remark was made by Raymond when he saw architects Albert Kahn's own house, on one of his business trips to America which he conducted in order to obtain a commission from Henry Ford to build a large assembly facility in Japan.

His work at that time was creative and modern in every way; I was, therefore, amazed to find that both his office and his home were designed in an entirely eclectic way. It was difficult for me to understand how those two things could be reconciled in one personality, as both aspects could not be the expression of a truly sincere conviction. [10]

A similar situation is L. Hudec's experience; both of his houses were designed following the local trend of eclecticism and classic revival. He was somehow more aiming towards the comfort of the family in the detriment of the modern form and the development of new trends in the history of architecture. Hudec might had been influenced by his wife's wishes and classic stylistic preferences (as we can see in the numerous drawings and details of the furniture designed for Gisela's bedroom) and another reason could be his financial business skill, since he was very good in making investments and gain profit 
after selling the property. The styles chosen for their family houses were not defining the architect's vision of a perfect, modern work of art, but may rather reflect the overall preference of future possible clients, proving that Hudec was more interested in business than creating outstanding designs. An exception was Hudec's Sun Ke's house [7]. It seems that the architect designed it in a freer, creative mood, perhaps because the house was originally meant for him, and some traces of shifting towards new modern trends were just around the corner. Since he did not have to please any client, he felt the freedom to indulge himself in experimenting with his own ideas. Since he got a very good offer from Sun Ke, he sold the house before it was completely finished, just another proof of his ambition por profits that may enhance his practice (Fig. 12).
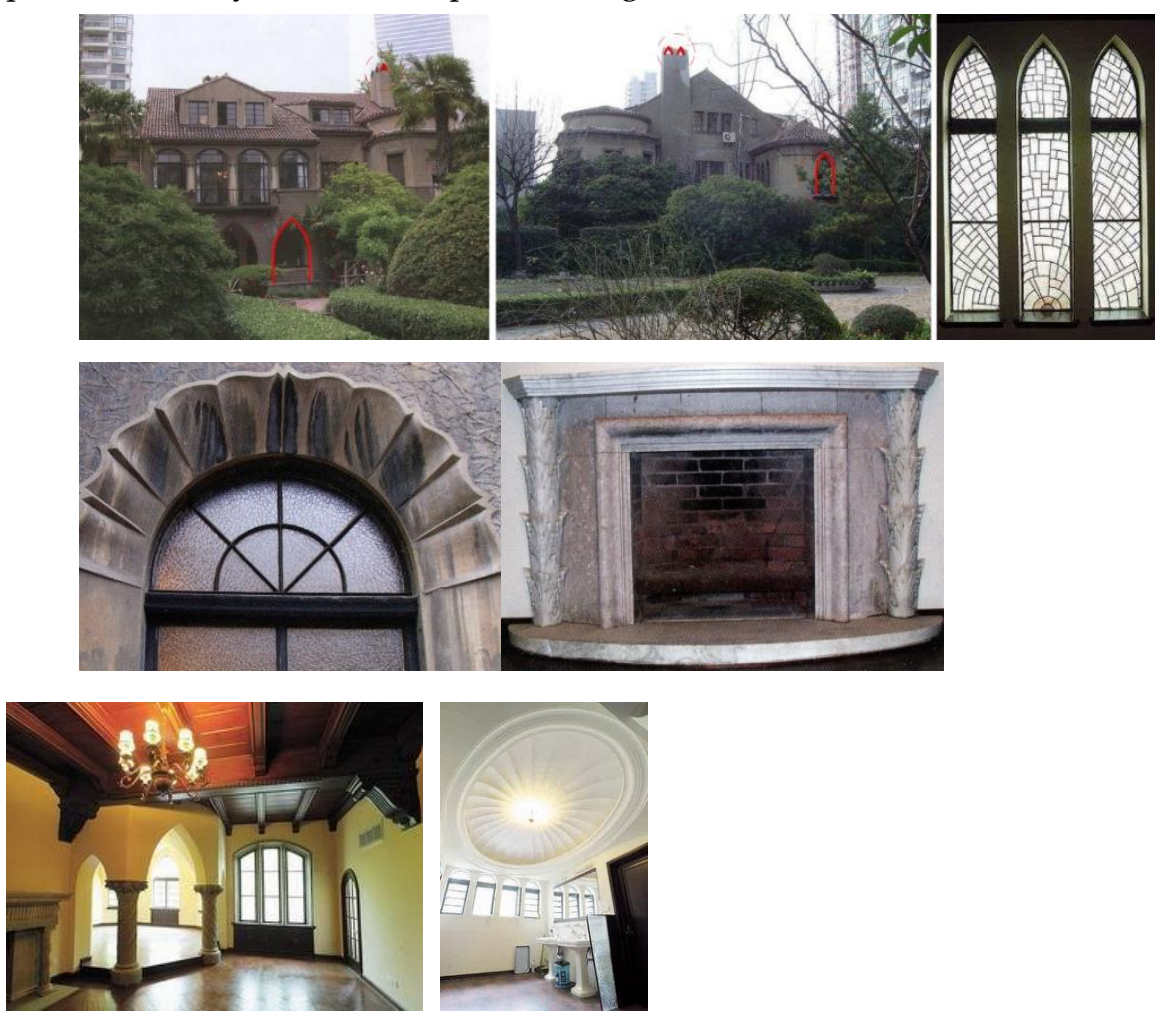

Figure 12. Sun Ke House, neo-gothic (first row) and art nouveau (second row)

Hudec's second residence built in 1930 was one of Hudec's last projects belonging to his first period in his independent career, described as a constant continuity of Classicism and Eclecticism designs, for a variety of clients, of different nationalities (westerners and Chinese) and cultural backgrounds. The designs he made in this first phase of his career were all eclectic. This required extensive and vast knowledge. His theoretical background acquired in the University years helped him greatly. He was aware of Frank Lloyd Wright's activity, and like Antonín Raymond, he disagreed with the way he was imposing his designs and ideas, no matter the taste or real need of the client. Raymond and Hudec always designed their projects for and with the clients, analysing and filtering the requirements depending on environmental characteristics and wishes.

He felt at home with a wide array of architectural styles, always choosing the one that best suited the taste of his client. He worked like an extremely adroit tailor who makes 
bespoke clothes, in all sizes and designs, from any material and in any quantity. His ultimate aim remained the same throughout his career: to satisfy his clients as best as he could. [...] Hudec believed that the architect must serve the client and the community. [2]

Later on, he was to apply his novel ideas into Dr. Woo's house which was recognised as an early and enduring influence by the Chinese architect I. M. Pei. In this occasion Hudec's approaches were much more systematic. (Fig. 13)

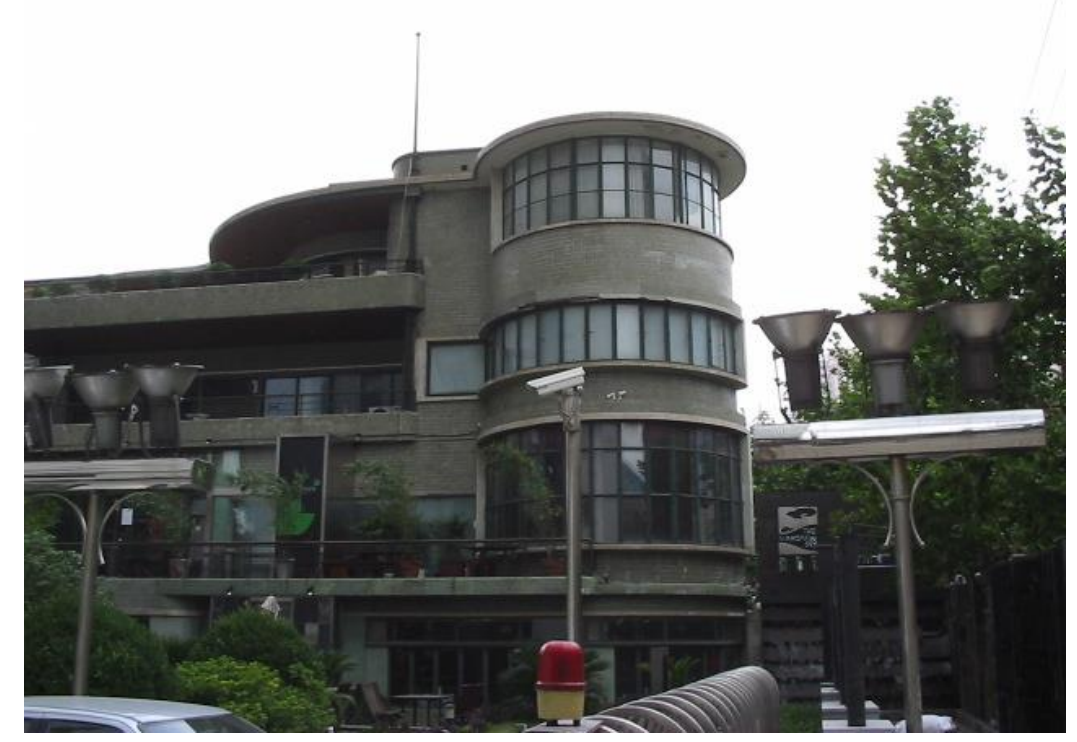

Figure 13. Former residence of Doctor Woo

\section{3.- The grander scale of L. Hudec}

In the early 1930s, Hudec's star was about to shine brighter with the construction of Shanghai's tallest skyscraper. He played a significant role in developing modern architecture in Shanghai, side by side with other prestigious architects of that time, who were slowly beginning to shift their neoclassical stylistic preferences in the direction of Art Deco, or the so-called "modern". Shanghai became in the 1930s, one of the major centre of Art Deco (still extant and well preserved), with a very high number of buildings around the Bund area. Shanghai's art deco is unique because of the traditional Chinese design elements that were incorporated.

His two designs developed almost in parallel, the Grand Theatre and the Park Hotel, which were situated in a centremost area, in the northern side of the Race Course, adjacent to each other. Figures 14 and 15, show the Race course and the Shanghai Race Club, a building that we can visit today, designed in neo-classical style (1934) with effective eclectic details. 


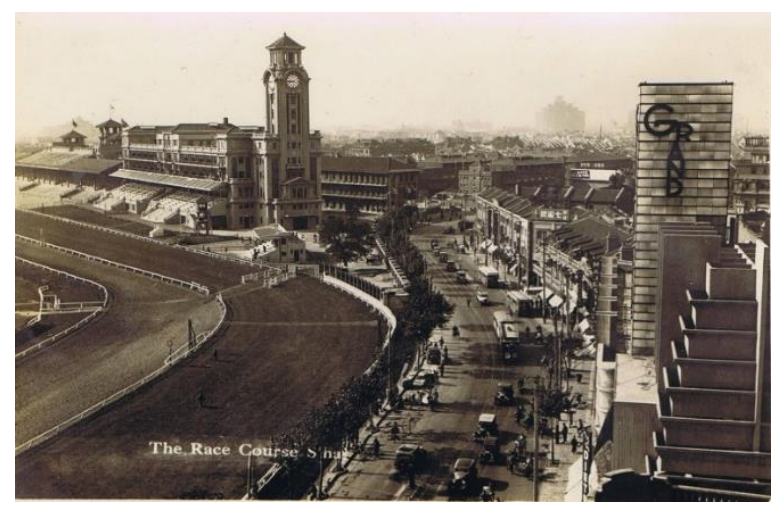

Figure 14. The race course with Shanghai Race club and Grand Theatre, view from the Park Hotel

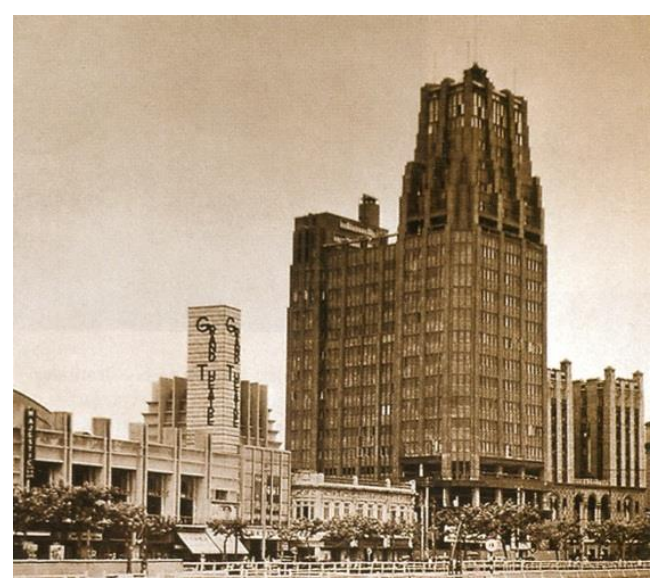

Fig. 15. View from the race course towards the Grand Theatre and Park Hotel

The 22 storeyed hotel (91.4 metres) was designed once again for the Joint Savings Society (after the previous success of the JSS headquarters). It was at that time and for many decades after, the tallest building in the entire Eastern Hemisphere, from London to Tokyo: Until 1984, for more than a half century the new structure was to remain the highest residential construction of Shanghai and Asia [7]. It was a dream come true not only for the architect but for the Shanghainese citizenship who were enthusiastically aiming toward modernization. Since the American skyscrapers equalled and symbolised the modernity and financial power of the city, Shanghai became very proud of its own achievement. Hudec's recognition extended to internationality and he remained known until today as "the Man who changed Shanghai".

Shanghai lies on a very difficult alluvial soil, on the River Yangtze Delta, composed of sand and mud. This was always problematic for the builders, because after a short time, all the constructions start to sink or lean. Building in height seemed almost impossible. It was only in the first decades of the 20th century that European engineers invented new technologies and methods of foundation, suited for Shanghai's impractical soil condition, with the aim of reducing to a minimum the subsidence problem. In order to receive the permit to erect the Hotel, the architects had to present a satisfactory foundation design that would prevent such constraint and reduce the sinking to a minimum:

The plan offered three special solutions: a deep foundation pit to be excavated, impermeable metal partitions to surround it, and the insertion of a dense system of piles. 
Four hundred 33-meters-long piles of Oregon pine were driven into the ground at a close distance in order to increase friction coefficient between the piles and the soil to ensure an adequate transmission of the building loads. [2]

Beside the already mentioned system of piles, Hudec and his team adopted another method, developed in 1920 in Germany, called the Larsen pile profiles, which consisted in piles made with sheets of steel, driven in the ground in order to stabilise it. Pile foundations had been previously employed in Eastern Asia since the early 1920s, but never before for such a high building as the Park Hotel.

The building features 22 storeys above ground and 2 storeys below the ground. Resembling the skyscrapers from New York, from the ground until the upper $21^{\text {st }}$ floor, the layout and form is constantly changing, gradually decreasing, thus creating a truncated pyramid shape towards the sky that begins at the $15^{\text {th }}$ level. The whole composition and syntax is based on a characteristic tripartite scheme used by the architect in most of his high-rise buildings:

3.3.1.- The base of the hotel showcases modern details such as, emphasis on the horizontal, dark finishes of polished black granite from Shandong and Qingdao, rounded corners and continuous windows following the same major curve of the road (a detail he previously included in 1928 for his neighbouring design, the Honisberg Garage, by virtue of the same architectural language which later became known through Erich Mendelsohn's work in Wrocław).

Thus, the architect managed to integrate the appearance of the lower levels of the hotel (Fig. 16) with his previous design for the Honisberg Garage, it almost seems like the two building were meant to coexist. Unfortunately, the garage was recently demolished in order to accommodate a major expansion of the hotel.

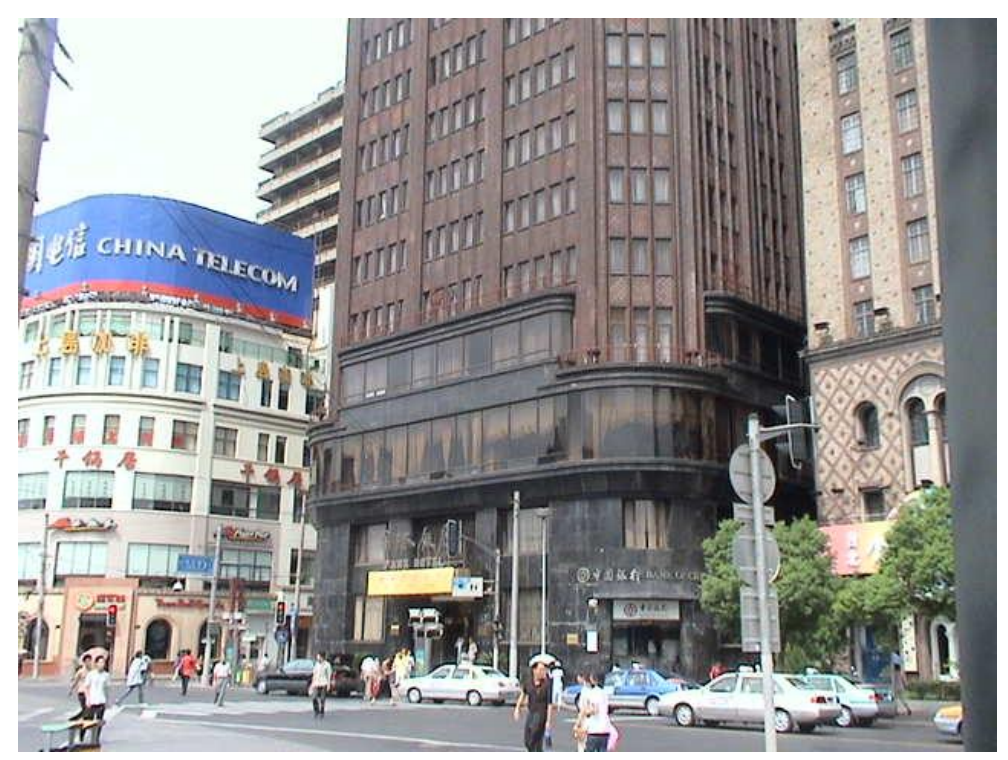

Figure 16. Lower levels of the Park Hotel

3.3.2.- The middle section, entirely Expressionist in style, is clad with dark brown brick and ceramic tiles. Vertical elements that convert into rear pillars articulating and dividing the façade, present at the same time a decorative and functional role, these elements provide grace and cause the building look sleeker than it actually is. 
Between the modern rectangular shaped windows, the vertical brick faces are laid in 45 degrees from the horizontal (a resource visible in the building of the Christian Literature Society for China). The ceramic enamelled tiles covering the facades are rotated again by 45 degrees, creating interesting textures which vary in subtle accordance with the angle of the sun. Although Hudec resorted mainly to German Expressionism, his meticulous design with oriental furnishings, proved a sensation, since buildings so hefty and monumental were yet to emerge at the time.

3.3.3.- The upper section, purely Art Deco and Expressionist, bears finishing alike to that of the middle floors (dark ferrous brick and enamelled tiles). The stepped pyramid of the upper part, which reminds us of Saqqara, emphasises the verticality and slender silhouette of the entire building. The windows use the same grid-like disposition. The attic recesses floor by floor until the top, where an observatory terrace was placed (Fig. 17)

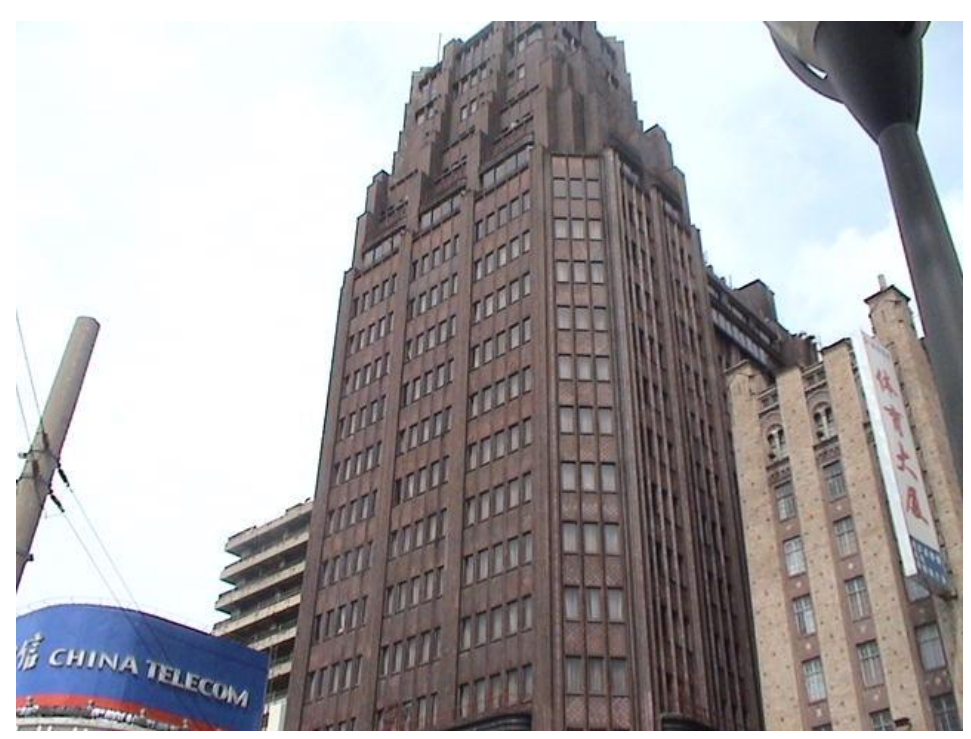

Figure 17. JSS Building (Park Hotel), main view, detail of the façade decoration from the middle part and detail of the upper part.

In fig. 18, we present a succinct analysis of the façade's grammar and the vector-like interplay of tension lines. Such careful composition reveals the sheer evolution of Hudec's architectural thinking towards a modern idiom. 


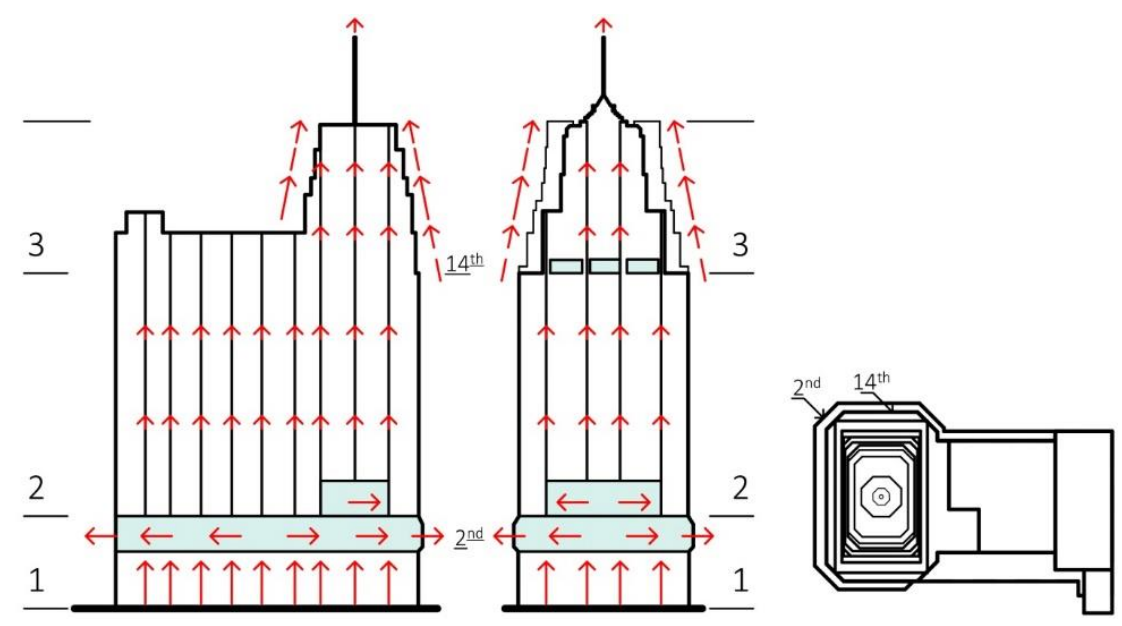

Figure 18. JSS Building tripartite scheme and gradually decreasing plan. Scheme of tension lines.

In 1931, Hudec was commissioned with the refurbishment of the Grand Cinema built in 1928. Initially the design was meant to become a temporary facility. However, Hudec persuaded the clients to go ahead with the construction of a new, modern movie theatre, which resulted in his most significant design made for the world of entertainment.

The site was near to the Park Hotel, as the two buildings positively contributed to the definition of the cityscape of 1930s Shanghai. Art Deco and Modern style, straight and curved tension lines which mark the whole aspect of both the exterior and interior of the Grand Theatre (Fig.19)
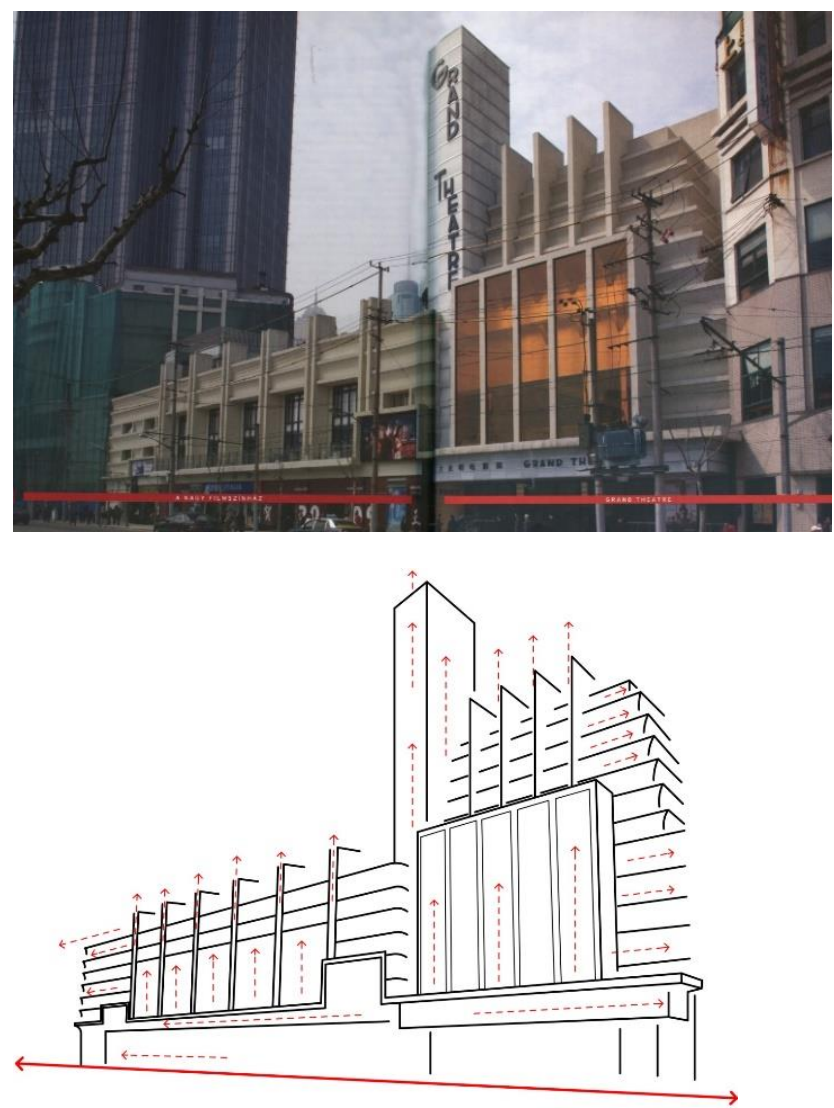

Figure 19. Grand Theatre, Up: main view from the former race course. Down: compositional study of the façade's grammar, art deco and international style. 
Perhaps facing less constraints that in the case of the Park Hotel, Hudec envisaged here a true liberation of forms towards a futuristic expression. One that encompassed the fascination of the Orient with advances in technique and signified a real progress for Chinese Architecture.

The architect's dexterity to fit all the required spaces into such a difficult, quasi triangular plot (long and asymmetrical) can be seen in the way he devised to project the entire building.

The structure of the central hall's gallery was a sort challenge for the engineers, but the result was satisfactory. Taking into account its dimension, it constituted a real novelty in the Far East. The shape of the main hall and the reinforced concrete arch gallery ensure proper visibility and adequate acoustics from all the seats (Fig. 20).

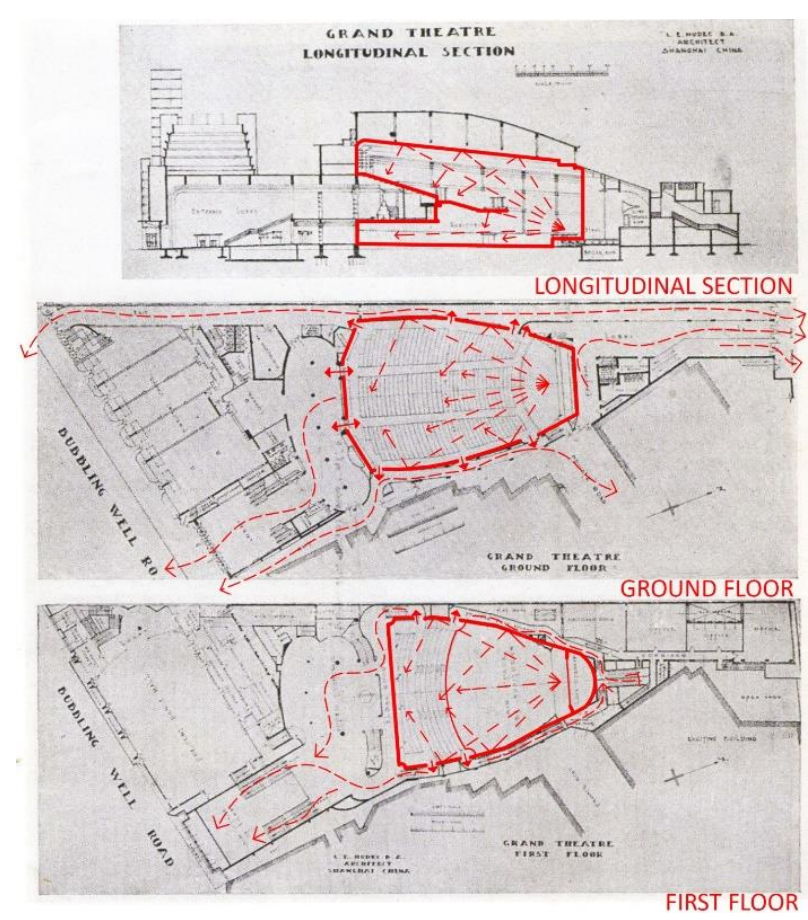

Figure 20. Grand Theatre, longitudinal section and plans- shape, acoustics, visibility and evacuation of the auditorium.

Carrier's air conditioning equipment (which amounted to $25 \%$ of the total construction costs) and fire control systems were installed in the entire building. By that time, it was the sole cinema in Shanghai equipped with synchronous interpretation devices integrated into each chair. Because of that, barriers of language were almost broken and everyone, even locals, could attend the latest foreign-language American and European films through individual earpieces. The programme changed in order to reflect the developments of the Chinese film industry only after the Pacific War, in 1949.

With the Grand Theatre's refined statement (Fig. 21) and the landmark of the Park Hotel, Hudec returned to the spot light, this time in the international scene of Modern 
Architecture, side by side with leading architects of the period, gaining his recognition through sundry publications.

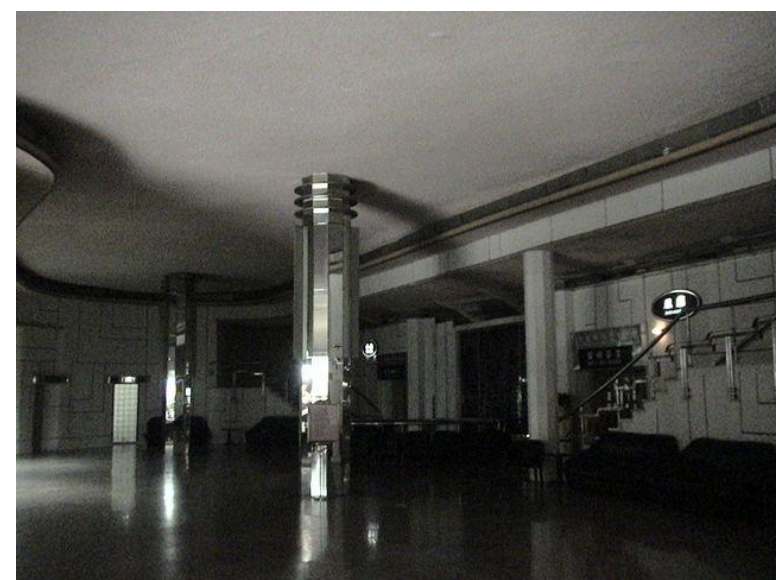

Figure 21. Grand Theatre, the entrance lobby and glittering pillars.

The September 1934 issue of L'architecture d'Aujourd'hui introduced the Grand Theatre in a lengthy article along with some designs by le Corbusier, the Moscow Theatre designed by the Vesnin brothers and the famous London Zoo pavilion of Lubetkin and Tecton. The issue of May 1935 of 'Der Baumeister' published the designs of the Park Hotel and the Grand Theatre side by side: the two buildings stand next to each other and together defined the skyline of Shanghai at the time. In December 1935 Dexter Morand wrote about the Grand Theatre in the Spanish journal 'Obras': This new cinema is neither European, nor American, but Asian and Chinese. It testifies to the high standard of film theatre construction achieved in this country and is on a par with European cinemas. The layout and decoration of Shanghai's Grand Theatre (Fig. 22) are as modern as any European or American design could be. Its appearance bears the marks of Modernism often seen in Europe. [2]

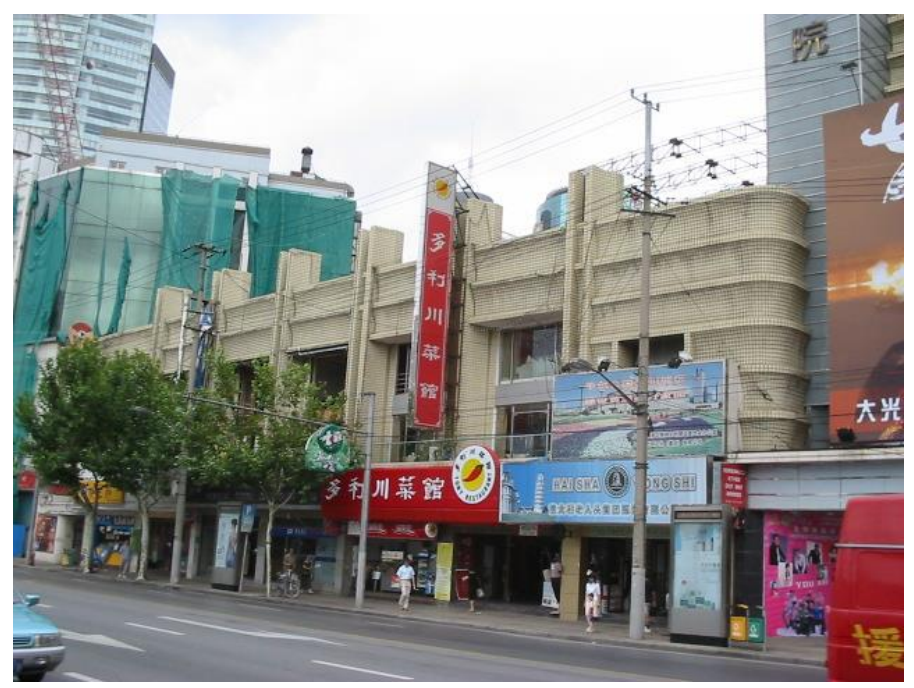

Figure 22. Recent view of the Grand Theatre. 


\section{4.- Discussion}

As seen in the projects described, Raymond's trajectory towards modern architecture was much more straightforward, as compared with Hudec's long and winding road.

Hudec and Raymond's visions on how an architect should behave, converge as follows:

Independence and freedom are two important aspects, vital to an architect or artist, in order to protect their creative work from anything that might compromise it. A real architect must be an independent artist. He must have freedom and strength to stick to his principles. [11]

But, besides that, an architect has to be able to do beautiful and economical architecture even in the worst situation possible: It is the architect's job to create beauty in every house, no matter what the economic level is. [12]

Discussing on the relationships between architecture and engineering, we have to stress out that both Hudec and Raymond enjoyed a similar Polytechnic academic formation. The two central European universities, Budapest and Prague, belonged to the Austro-Hungarian realm and as such, they were putting a great emphasis on the proper education, an engineering preparation of their students. But, due to their different cultural context of living and designing, the two architects ended up having different orientations. Hudec is perhaps more of "the engineer" type and Raymond closer to "the artist" as can be perceived in their way of thinking and designing.

Although this slight difference existed, both of them had considered vital the collaboration between the architect and the engineer. As Raymond stated, they must:

$[\ldots]$ work hand in hand [...] from the beginning (of the project), in order to find not an extraordinary solution, but the simplest, the most direct and most economical solution of the problem. [12]

Soon, he realized that in order to eliminate any kind of constrains due to future possible confrontation with engineers, an architect had to become one with himself in order to achieve his aims, and more, in the technological present era, an architect needs to know the properties and technological processes of different materials:

The aim of the architect is to put once more his feet on the ground, to work naturally and from insight, to avoid external artistic and abstract influences, to become once more an "Architect" which means "Master-Builder". Designers, whether they are architects or designers for the industry, have, as a rule, little idea how their designs are to be executed. [13]

This was enhanced by the context of Japan, where previously, the profession of an architect did not exist and the carpenter or Daiku, had the role of an architect and engineer at the same time. [6]

Hudec, on the other side, regarded himself as an engineer rather than an architect. The technical aspects, structure and construction techniques were part in the process of defining the architectural form, being equal in importance, always seeking for unity and 
interaction between them: You will only be a good architect if you understand materials and construction. [...] Here buildings have either steel or reinforced concrete frame structure, walls are not considered structural elements but seen just as partitions. [2]

Their conscious pursuit of the oriental ways of building, the so-called Dao of architecture led them to a spatial renovation that paradoxically coincided with some postulates of modern architecture as recognised by Walter Gropius on a famous postcard to Le Corbusier in which he admitted among other statements that, "the Japanese house is the best and most modern I know of and truly prefabricated".

By accepting the modularity and versatility of the oriental construction procedure which is based in the Jian or Ma system of intervals, $[9,13]$ as we exposed regarding the Karuizawa summer house, they paved the way for an early space syntax applicable not only in Asia but in the whole world like Bruno Taut had justly foreseen during his stint of three years in Japan. A fact later confirmed by Schindler, Neutra and even Bernard Rudofsky in his acclaimed essay "The Kimono Mind".

Moreover, such semiotic paradigm reached contemporary linguistic theories when Roland Barthes published in 1970 the book, Empire of Signs about his experiences in contemporary Japan.

In his celebrated lecture the Destruction of the Box, addressed to the AIA in 1954, Wright expresses his admiration with a vision of LaoZi contained in The Book of Tea by K. Okakura:

He claimed that only in the vacuum lay the truly essential.

The reality of a room, for instance, was to be found in the vacant space enclosed by the roof and the walls, not in the roof and walls themselves.

It can be argued that in a similar fashion to their former master, Frank Lloyd Wright, they adopted the following vision of LaoZi about architectural space:

Pottery need to be hollowed so that it is useful, (otherwise it is just an irregular brick) a house needs to have some holes (e.g. door and windows) to be useful, (otherwise air and people cannot enter or exist). Thus, a certain level of nothingness is necessary to make an object useful.

That is, for them, the void is more important than the solid, a game-changer for design since Aristotle had postulated that the void was irrelevant compared with the matter.

\section{5. - Conclusion}

Hudec and Raymond are justly called pioneers of modern architecture because they were among the first western architects who came to Eastern Asia (in a completely different cultural context from their native one), developed as modern architects and managed to guide, transform and implement a new way of thinking and design based on oriental philosophy. 
Once in Japan, far away from his native Europe, Raymond had to adapt his design processes. So, he tried to define what he considered to be the principles of a true modern architecture, everything based on the synthesis between his own pre-Japan experience and what he had learned since his arrival in Tokyo- space, structure. modulation and philosophy of Japanese traditional architecture.

Antonin Raymond, found himself in a relationship with Japan that offered him the best conditions for developing his stark principles. Nature goes hand in hand with beauty, and beauty, in the traditional Japanese houses, was to be found in pure simplicity. It was only after years of experience and observation of the Japanese houses, that he realized of the easiest way to achieve beauty in architectural design: It is through increased simplicity and elimination that the man of taste finds elegance.

Hudec's modernism lies in his architectural ability and complexity, as a man always ready to change his life drastically when confronted by dire events or facing necessity. He gained architectural experience in Shanghai (not as the leader of the architectural movements but always prepared to follow and to adhere to new trends and styles if his clients were wishing for, constantly adapting to the fashion and introducing latest western technologies in the Far East), diplomatic experience during the Second World War (providing humanitarian aid, helping his compatriots and Jews from the Nazi prosecution) and teaching experience in America (giving lectures on archaeological themes).

Hudec was not as avant-garde as the trend-setters European contemporaries, who were concerned about reforming and creating new guide lines in architectural design. But, thanks to his dexterity in articulating Modern functions, spaces and shapes with the worlds most advanced technologies, he became one of the leading architects of the fashion in Shanghai, enjoying local and international recognition through his designs that deeply reflected the city's growth and cultural character in the constantly changing Chinese society.

Both should be praised for their stylistic audacity that heralded a new understanding and appreciation of architectural space.

Author Contributions: Conceptualization, A.A.A. and J.C.-L; methodology, J.C.-L; investigation, J. C.-L. and A.A.A.-C.; writing-original draft preparation, J.C.-L. and Y.X.; writing-review and editing, J. C.L.; visualization, Y.X. All authors have read and agreed to the published version of the manuscript.

Funding: This research received no external funding

Acknowledgments: A.A.Anghel. dedicates this article to her family. J. Cabeza-Lainez would like to recognize the consistent help of Riko Katsube and Lavinia Mates. Y.X. Appreciates the understanding and support of her family and especially of her beloved daughter Tanya.

Conflicts of Interest: The authors declare no conflict of interest. 


\section{References}

1. Cabeza-Lainez, J.; Jiménez-Verdejo, J.R. The Japanese Experience of Environmental Architecture through the Works of Bruno Taut and Antonin Raymond, Journal of Asian Architecture and Building Engineering, 6:1, 33-40. https://doi.org/10.3130/jaabe.6.33

2. Poncellini, L.; Csejdy, J.: Hudec László - Az építész mesterei - Könyv (LÁSZLÓ HUDEC. Masters of Architecture). Holnap Kiadó, Budapest, 2010.

3. Antonin Raymond: Concrete for New Designs. The Architectural Record 79. January 1936, p.7.

4. Cabeza-Lainez, J. Notas para una biografía arquitectónica: Antonin Raymond, Nociones de Japonisme. Revista de Historia y Teoría de la Arquitectura (2002). (1576-5628).Nr. 2. 5-44.

5. Antonin Raymond: An Autobiography. Charles E. Tuttle Co., Inc., Japan, 1973.

6. Cabeza-Lainez, J. Lighting features in Japanese Traditional Architecture. In Lessons from Vernacular Architecture. (2013) Routledge. ISBN9780203756164.

7. Jánossy Péter Samuel - Deke Erh: HUDEC LÁSZLÓ - Élete És Munkássága - Az Igazi Homo Ludens (Life and Work of HUDEC LÁSZLÓ - The Real Homo Ludens). Építésügyi Tájékoztatási Központ Kft. Budapest, 2010, p.258.

8. Cabeza-Lainez, J.M. Fundamentals of Luminous Radiative Transfer; Netbiblo: Seville, Spain, 2010. (In Spanish).

9. Salguero Andujar, F.; Rodriguez-Cunill, I.; Cabeza-Lainez, J.M. The Problem of Lighting in Underground Domes, Vaults, and Tunnel-Like Structures of Antiquity; An Application to the Sustainability of Prominent Asian Heritage (India, Korea, China). Sustainability 2019, 11, 5865. https://doi.org/10.3390/su11205865

10. Cabeza-Lainez, J. The Quest for Light in Indian Architectural Heritage. Journal of Asian Architecture and Building Engineering (2008), 7:1, 39-46, doi: 10.3130/jaabe.7.39.

11. Kerr, A.; Sokol A. K. Another Kyoto. 2018. Penguin Press. ISBN-13: 978-0141988337

12. Gloaguen,Y. Towards a definition of Antonin Raymond's "Architectural Identity" : a study based on the architect's way of thinking and way of design. Thesis or Dissertation, Kyoto University, 2008. extract from Antonin Raymond's lecture "Housing- A Post War Responsibility and Opportunity" (Lecture on Building at the New York Institute of Finance), 1945.

13. Rodriguez-Cunill, I.; Gutierrez-Villarrubia, M.; Salguero-Andujar, F.; Cabeza-Lainez, J. Sustainability in Early Modern China through the Evolution of the Jesuit Accommodation Method. Sustainability 2021, 13, 11729. https://doi.org/10.3390/su132111729

14. Kurt G. F. Helfrich and William Whitaker: Crafting a modern world, the architecture and design of Antonin and Noemi Raymond. Princeton Architectural Press, New York, 2006, p.302 